

http://jyd.pitt.edu/ | Vol. 16 Issue 5 DOI 10.5195/jyd.2021.1089 | ISSN 2325-4017 (online)

\title{
Sociopolitical Participation Among Marginalized Youth: Do Political Identification and Ideology Matter?
}

\author{
Aixa D. Marchand \\ Rhodes College \\ marchanda@rhodes.edu \\ Michael Frisby \\ University of Michigan \\ mfrisby@umich.edu \\ Maura R. Kraemer \\ University of Notre Dame \\ mkraeme2@nd.edu
}

\section{Channing J. Mathews}

North Carolina State University

cjmathew@ncsu.edu

\section{Matthew A. Diemer}

University of Michigan

diemerm@umich.edu

\section{Adam M. Voight}

Cleveland State University

a.voight@csuohio.edu

\section{Abstract}

Engaging youth in the political system has promise for creating social change and ensuring the future of our democracy. Sociopolitical participation-individual and/or collective action to facilitate change-may be biased towards more liberal or Democratic views, which emphasize reform to create social equity. The aim of this study is to test if youth who vary in political ideology (i.e., conservative, liberal) and political identification (i.e., Republican, Democrat) participate at different levels and whether this measurement of sociopolitical participation is in fact biased. These issues were examined among 237 youth attending a large Midwestern high school who generally identified with historically marginalized groups. Results

\section{(cc) EY} New articles in this journal are licensed under a Creative Commons Attribution 4.0 License.

This journal is published by the University Library System, University of Pittsburgh and is cosponsored by the University of Pittsburgh Press. The Journal of Youth Development is the official peer-reviewed publication of the National Association of Extension 4-H Youth Development Professionals and the National AfterSchool Association. 
suggest that youth identifying as Republican exhibited slightly higher levels of participation, and that items were not biased by political ideology or identification. Further, political ideology and identification explained less than $5 \%$ of the variance in sociopolitical action, suggesting it is largely independent of political leaning.

Key words: critical consciousness, marginalized youth, MIMIC models, sociopolitical development

\section{Introduction}

A strong democracy is created when all perspectives and voices are included in the conversation and political process. Specifically, with youth, there is great potential for the development of novel ideas and social change when their voices are heard in the political arena (Watts \& Flanagan, 2007). In the current political moment, we are observing perspectives from across the political spectrum being shared. From COVID-19 mask bans, critical race theory bans in schools, abortion rights rallies, and protests against racist police force-individuals from diverse political standpoints are speaking out and advocating for their beliefs and issues that are important to them. With that, it is of great importance to understand if the political leanings of diverse youth influence their engagement in the civic and political spheres of society, in an increasingly partisan nation. With that, this research explores whether there are differences in sociopolitical participation depending on how youth identify with either political party (i.e., Republican or Democrat) or political ideology (conservative or liberal) and whether the measurement of this participation is also biased.

\section{Critical Consciousness and Sociopolitical Participation}

Definitions of civic and political engagement have become increasingly inclusive and recognize both the "conventional" and "social-cause" efforts to help others, improve the community, and/or shape the future of society both at an individual and collective level (Adler \& Goggin, 2005; Torney-Purta et al., 2001). Further, civic and political engagement for youth encompasses the behaviors and actions they are participating in to make social and political change including volunteering for political campaigns, community organizing, writing and signing petitions, activism, and joining civil rights organizations (Diemer et al., 2017; Gaby 2017; Watts \& Flanagan, 2007). Shifts in what constitutes this engagement enables us to examine these political processes within youth samples. Youth often have not been considered within political spaces because engagement has generally been viewed narrowly as voting, volunteering, and donating to political campaigns-activities that are largely inaccessible to youth in the United States below the age of 18. However, even without the legal ability to vote and contribute to our democracy in that way, youth are active and contributing socially and politically. By using definitions and measures that are inclusive of activities that youth are participating in, we can get a better sense of how they are engaging within the political system. 


\section{Youth Sociopolitical Participation and Views}

Sociopolitical participation is conceptualized within various theoretical frameworks such as sociopolitical development theory (SPD) and critical consciousness ([CC]; Watts et al., 2011; Watts et al., 2003). Both frameworks share roots in the pursuit for liberation through identifying one's ability to critically analyze social inequities, their motivation and perceptions of their ability to make social change, and the actions they engage in. CC, a concept developed by Paulo Freire (1993), has been identified as an important correlate to many positive youth outcomes, including political participation among youth from marginalized backgrounds (Diemer \& Li, 2011; Diemer et al., 2016; Watts et al., 2011), and has been considered an "antidote for oppression" (Watts et al., 1999). Sociopolitical action-or the more behavioral component of CC-refers to the actions individuals take to improve issues within society that are perceived to be unjust.

Examining sociopolitical participation with marginalized adolescents is particularly important due to historical, contextual, and developmental realities they face. Individuals marginalized socially or economically experience sociopolitical barriers such as social exclusion and limited access to opportunities. These experiences may shape how marginalized youth think about social injustice and catalyze the actions they take towards redressing these issues (Ballard, 2016; Hope et al., 2019). Participation in these actions has been found to have positive outcomes. For instance, in samples of racially marginalized youth, this engagement has been found to be associated with self-expression, solidifying community bonds, and the ability to navigate negative emotions they experience (DeAngelo et al., 2016; Ginwright, 2015; Hope \& Spencer, 2017; Ortega Williams et al., 2020). Because research focusing on sociopolitical action has documented associations with positive well-being, it is important to study how youth who identify differently across different social markers are engaging in actions that are believed to be unjust. Sociopolitical participation allows for youth to advocate for issues that are important to them and to assert their voices (Diemer \& Rapa, 2016; Hope et al., 2016).

Adolescence is a period marked by increased exploration in metacognition, abstract thinking, and social cognition, which actively contribute to identity exploration and development of sense of self, individually and in context (Bronfenbrenner, 1979; Erikson, 1968). This growing ability to recognize and analyze social surroundings while understanding their place in the world makes adolescence an important time for youth to examine the development of CC, political behaviors, and sociopolitical participation. Especially for adolescents of color, increased exploration of racial/ethnic identity strengthens their ability to recognize both individual and structural level discrimination, racialized experiences, and creates the desire for them to process and engage in action (Anyiwo et al., 2018). 


\section{Political Attitudes and Behaviors}

Individual's perspectives about society are reflected in their political views and identification with a political party. Political party identification is most commonly referred to as Republican or Democrat. Another way to think about differing political attitudes is by examining ideology, which is conceptualized as a continuum from liberal to conservative, and refers to an individuals' views on social change and social inequality (Patterson et al., 2019). Ideology and identification are related but not synonymous. Party identification has been found to be an important predictor of how individuals vote (Knight, 1999) and even within youth samples, has been found to be strongly associated with future political participation (Wray-Lake et al., 2019). However, along with ideology it is uncertain whether political identification is associated with the sociopolitical participation of marginalized youth.

Since sociopolitical participation is grounded in a CC framework, the associated attitudes and beliefs tend to be viewed as more critical in nature due to the fact that theoretically there is a stated commitment towards liberation, which some would argue is a more left-leaning perspective (Watts et al., 2011). Therefore, a question remains: Is youth participation in sociopolitical action biased toward more liberal or Democratic notions and how does that action vary among youth from different social backgrounds?

\section{Liberal Bias in Measuring Sociopolitical Participation?}

There are still empirical and practical needs to more fully understand sociopolitical participation in marginalized youth, specifically those that may face oppressive structures due to race and poverty. Although there is documented promise for engaging youth in these various political actions, research has found that there are serious participation disparities (Gaby, 2017; Laurison, 2016; Verba, 2003). Whether youth engagement in sociopolitical participation varies by perceptions of the societal status quo or by political perspectives is a key contribution that has yet to be examined. It stands to reason that sociopolitical participation-which centers activism and societal change rooted in a pursuit for liberation-may reflect a left-leaning perspective and therefore be biased in favor of Democratic and more liberal perspectives. If this is indeed true and Democratic or more liberal-identifying youth are participating at higher levels than Republican or conservative-identifying youth, it would be an additional problematic political engagement disparity that needs to be understood and addressed. By understanding how sociopolitical participation may or may not be biased can help identify levers to increase the political development and engagement of those who have historically engaged at lower levels. 


\section{The Current Study}

The current study seeks to understand the extent to which sociopolitical participation is explained by political ideology (i.e., conservative vs. liberal) and political identification (i.e., Republican vs. Democrat) among youth who are marginalized-defined as those who are either experiencing socioeconomic or racialized forms of marginalization. Additionally, we seek to explore whether items measuring sociopolitical action are potentially biased. To address this first research question, we apply multiple indicator and multiple causes (MIMIC) modeling and will analyze latent mean differences. Further bias present within the measurement of sociopolitical participation would indicate that the measure is not accurately capturing participation across the full political spectrum and would bring into question any results found using this measure. As a subsequent analysis, we test whether levels of sociopolitical participation varied by gender, race/ethnicity, and socioeconomic status (SES) and if items are biased by these social identities.

\section{Method}

\section{Sample}

The data used comes from a larger project which examines marginalized youths' critical consciousness (Diemer et al., 2019). The data consists of 237 public high school students who were predominantly seniors (51.9\%). The average age of the sample was 16.9 years ( $M_{\text {age }}=$ $\left.16.91 ; S D_{\text {age }}=1.25\right)$, with approximately $55.7 \%$ identifying as female, and $44.3 \%$ identifying as male. The majority (77.6\%) of youth self-identified as a student of color (American Indian or Alaskan Native $=0.4 \%$; Asian or Pacific Islander $=2.5 \%$; Black or African American $=58.6 \%$; two or more races $=11.8 \%$; non-White Latino $=4.3 \%$ ). $22.4 \%$ of youth identified as White.

Participants indicated the highest degree of educational attainment by one or both parents. When attainment for both parents was provided, the higher of the two was used. Twenty-four students said the highest educational attainment of their parents was less than a high school diploma (10.1\%), 82 reported a high school diploma (34.6\%), 24 said a post high school certificate $(10.1 \%)$, and 83 said a four-year degree or above (35.1\%). Twenty-four students provided no response (10.1\%). Based on membership in disenfranchised racial/ethnic and/or social class identity categories, the urban-residing youth in this sample are presumed to experience heightened levels of marginalization (Cole, 2009; for previous studies using this conceptual approach, see Diemer et al., 2017). 


\section{Youth Sociopolitical Participation and Views}

\section{Measures}

\section{Sociopolitical Participation}

Youth in this study provided responses to the Critical Consciousness Scale (CCS), an empirically validated measure assessing CC in youth from historically marginalized backgrounds (Diemer et al., 2017). The original validation study found a Cronbach's alpha of 0.87 for the Critical Action: Sociopolitical Action subscale amongst marginalized, predominantly urban-residing youth. This subscale consists of nine items assessing the degree of youths' participation in individual and/or collective action to produce sociopolitical change. These items capture how frequently youth engage in targeted, socially aware activities such as protests or participation in political organizations. Each item is on a 5-point Likert scale ranging from never did this to at least once a week. Example items may ask respondents how frequently they "joined in a protest march, political demonstration, or political meeting" or "contacted a public official by phone, mail, or email to tell him or her how you felt about a social or political issue." Lower scores on this subscale indicate lesser degrees of sociopolitical participation, while higher scores reflect greater degrees of sociopolitical participation. With this sample, this subscale was internally consistent $(a=.83$; mean interitem correlation $[$ IIC $]=.37)$.

\section{Political Party Identification}

This research asked youth to identify the political party with which they most closely identify. Each participant was limited to one response from the following options: Democrat, Republican, independent, and other. Only $2.5 \%$ of participants did not respond to this question. Because both the "independent" (16.5\%) and "other" $(8 \%)$ responses may include participants from politically disparate views (e.g., Green Party or Libertarian), and because we were unable to disaggregate them into their corresponding parties, these categories were ambiguous with respect to participants' political identification. Therefore, participants identifying as either independent or other $(N=64)$ were omitted from analyses of political party identification. The familiar two-party sample therefore consisted of 144 Democrats (83.2\%), 29 Republicans (16.8\%). We used 0 to indicate Democrat-identifying youth, and 1 to indicate Republicanidentifying youth. This approach for determining party identification of youth has been used since early political socialization research (e.g., Jennings \& Niemi, 1968).

\section{Political Ideology}

This research asked youth to identify as slightly, moderately, or strongly conservative, or slightly, moderately, or strongly liberal. $57.7 \%$ of youth identified as strongly or moderately liberal, $18.5 \%$ identified as slightly liberal, $15 \%$ identified as slightly conservative, and $8.8 \%$ identified as strongly or moderately conservative. Responses were dichotomized into two 
groups, liberals ( $N=173,76.2 \%)$ and conservatives $(N=54,23.8 \%)$. There were 10 participants who did not respond to this question and were considered missing data and therefore not included in the analyses of political ideology. We used 0 to indicate liberalidentifying youth, and 1 to indicate conservative-identifying youth. This dichotomization of variables serves the function in MIMIC modeling of creating a clear delineation between groups otherwise defined on a Likert scale. Without dichotomizing, interpretation of mean differences of sociopolitical action or differential item function would be less clear, as the differences along continuous or Likert scale variables is less well-defined.

\section{Social Class}

In order to address our secondary research aim, we used social class as a predictor in both MIMIC models to evaluate the degree to which the sociopolitical participation measure may be biased against less or more affluent youth. Because these youth have not yet established their own educational attainment, occupational prestige, or income, social class was determined on the basis of the highest educational attainment of their parents (Diemer et al., 2013). Participants indicated whether their parents completed some elementary or junior high/middle school, junior high/middle school, some high school, high school, a vocational/technical certificate, an associate degree in vocational/technical school, a 2- or 4-year college degree, or a master's degree, teaching certificate program, or professional degree or higher. Educational attainment beyond a high school diploma was used as a marker for social class. The measure was dichotomized to provide a clear group delineation in the MIMIC model such that 0 indicated youth whose parents' highest level of education was a high school diploma or less (44.7\%), and 1 indicated youth whose parents' highest level of education was anything beyond a high school diploma (45.2\%).

\section{Race/Ethnicity and Gender}

Similarly, we tested whether there was bias by social identities including gender and race/ethnicity. Gender was used as an exogenous covariate (further explained in Data Analysis section below) in this study. We coded gender such that 0 was used to indicate youth identifying as female (55.7\%), and 1 was used to indicate youth identifying as male (44.3\%). Similarly, students' race/ethnicity was also used as an exogenous covariate. This variable was dichotomized between White youth and youth of color such that youth of color $(77.6 \%)$ were indicated by 0 , and White youth (22.4\%) were indicated by 1 . As with social class and political ideology, dichotomization along these lines was used to provide clear delineation between groups for clarity within the MIMIC model, and between youth groups likely to experience the greatest differences in degree of marginalization. Taken collectively with social class, a strong 
majority (88\%) of these youth are presumed to experience greater degrees of marginalization by identifying as a person of color, or coming from a poor and/or working-class background.

\section{Data Analysis Plan}

The central aim of this article is to explore the extent to which sociopolitical participation is biased by political identification and/or political ideology by identifying latent group differences. We use two MIMIC models to answer this question: one examining political party identification and the other examining political ideology. MIMIC models are an extension of confirmatory factor analysis (CFA), which use dichotomous exogenous covariates, such as liberal versus conservative, as well as other demographic variables to predict item-level and latent variable mean differences (Kline, 2015). Once the CFA confirms that the latent construct is a satisfactory fit to the data and that observed items measure the latent construct well, variables such as political identification are then added to assess differences in the latent construct and bias in the individual items.

MIMIC models also detect measurement bias by revealing whether the items reflecting the latent construct demonstrate differential item function (DIF). DIF occurs when members of a group (e.g., conservatives vs. liberals) produce different average responses to one or more of the individual items, even after mean differences in the latent construct have been controlled for. If DIF is detected, measurement bias is thus identified. Identification of measurement bias may suggest revision of this measure of sociopolitical participation, and should inform future research using this measure.

Other social identities such as race/ethnicity, gender, and social class may also reveal mean differences or measurement bias in sociopolitical participation (Diemer et al., 2016). Accordingly, we include three social identities: gender, race/ethnicity, and SES, as additional exogenous covariates to test this second set of research questions.

Figure 1 offers a conceptual depiction of our MIMIC model. To the left of the diagram are our four exogenous covariates: political ideology/identification, race/ethnicity, SES, and gender. Sociopolitical participation is depicted by a circle, indicating that it is a latent construct measured by individual items. The arrows pointing from the exogenous covariates to sociopolitical participation denote that sociopolitical participation is being predicted by these four variables. The arrows pointing from sociopolitical participation to questions 1 through 9 (see Table 1) denote that these items are being used to measure sociopolitical participation and are denoted by squares because they are observed variables. DIF, if detected, would be illustrated via arrows pointing from the exogenous covariates to the individual CCS item(s) exhibiting measurement bias. 
Figure 1. Conceptual MIMIC Model.

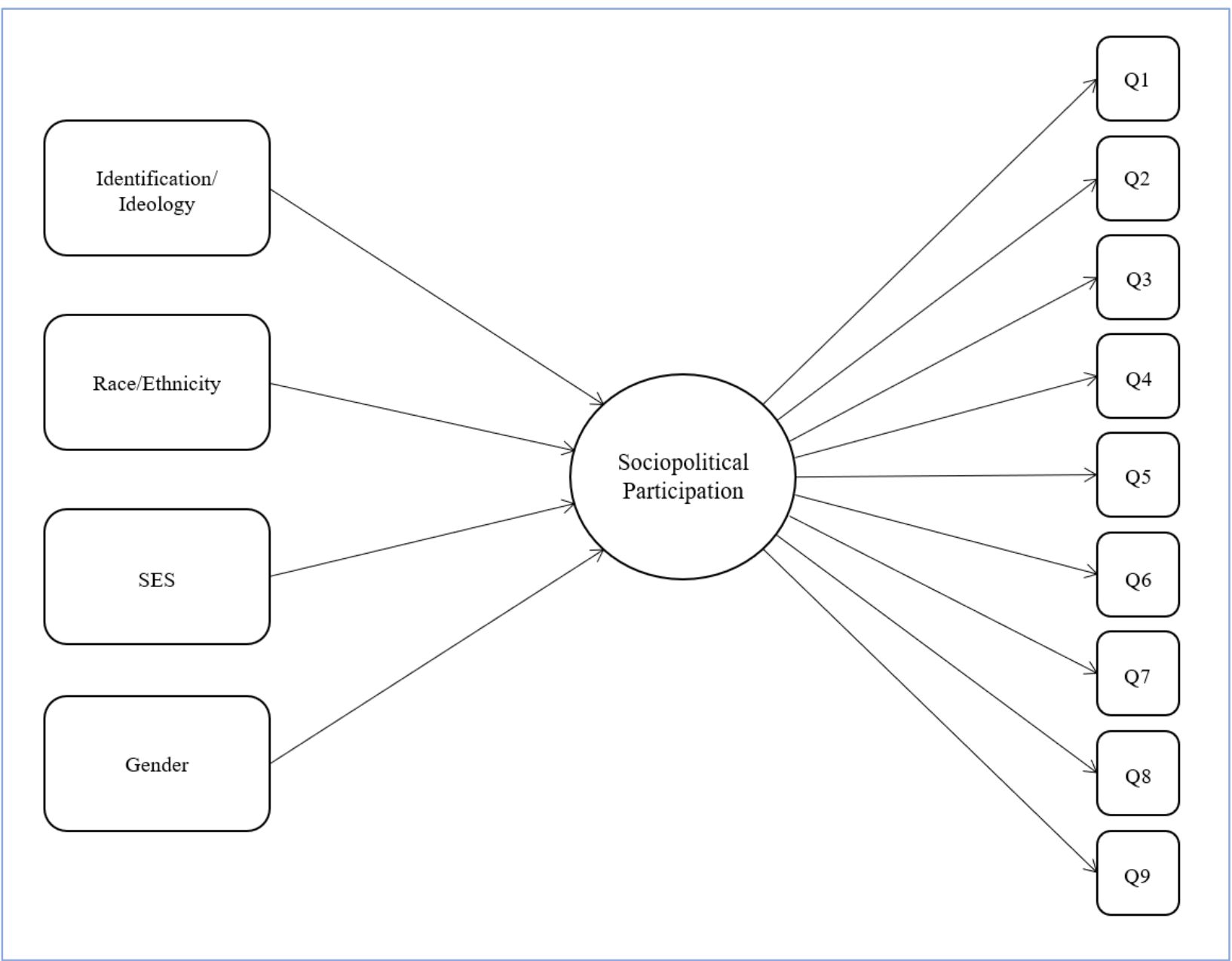

Sensitivity analyses were conducted by regressing an observed composite for sociopolitical participation - the average of the questions used in the sociopolitical participation scale-onto the four observed covariates. Two models were constructed: one using the political ideology covariate, and the other using political party identification. Ordinary least squares (OLS) regression was used for these sensitivity analyses. The goal of these analyses is to investigate whether the findings of the MIMIC models are corroborated by alternative approaches and allow for comparisons of total variance explained between the MIMIC and OLS regressions (coefficient of determination: $R^{2}$ ).

\section{Results}

Descriptive statistics corresponding to each item that measures sociopolitical participation can be found in Table 1. Missing data was limited, ranging from $0.8 \%$ to $3.4 \%$. Full information maximum likelihood (FIML) was used in all analyses to minimize information lost due to missing data (Enders \& Bandalos, 2001; Muthén \& Muthén, 2017 
Youth Sociopolitical Participation and Views

Table 1. Descriptive Statistics and Factor Loadings for Sociopolitical Participation Subscale

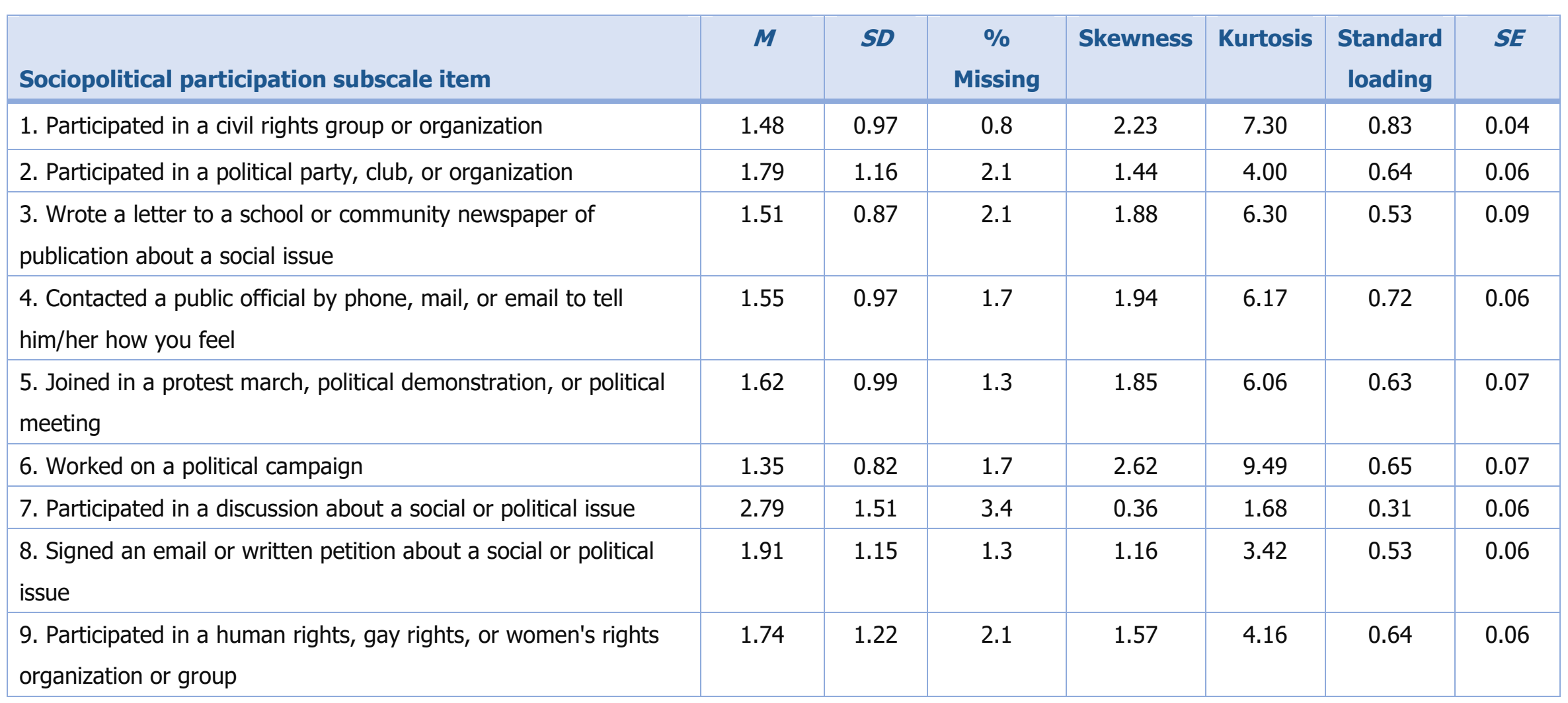

Note. Items were rated on a 5-point scale, ranging from 1 (never did this) to 5 (at least once a week). 
The relationships between all model variables are summarized in a Pearson correlation matrix (see Table 2). Sociopolitical participation here is represented by the observed composite measure of the items. It is important to note that correlations with sociopolitical participation as defined in Table 2 may differ from the findings of the MIMIC model. This is due to the construct being modeled as a mean in the Pearson correlation table, as opposed to being modeled as a latent variable in the MIMIC model.

Table 2. Intercorrelations Among Main Study Variables

\begin{tabular}{|c|c|c|c|c|c|c|c|}
\hline Variable & 1 & 2 & 3 & 4 & 5 & 6 & 7 \\
\hline 1. Age & - & & & & & & \\
\hline 2. Gender & $.20 * *$ & -- & & & & & \\
\hline 3. Race/ethnicity & $-.33 * * *$ & -.09 & - & & & & \\
\hline 4. Social class & $-.43 * * *$ & -.05 & $.23 * * *$ & - & & & \\
\hline 5. Political identification & -.02 & -.03 & .01 & .10 & - & & \\
\hline 6. Political ideology & -0.06 & -.12 & -.08 & .11 & $.31 * * *$ & - & \\
\hline 7. Sociopolitical participation & -0.03 & .003 & $.16^{*}$ & .004 & -.14 & .11 & - \\
\hline
\end{tabular}

Note. Reference category for each dichotomous variable is as follows: male for gender, White for race/ethnicity, more affluent for social class, Democrat for political identification, and liberal for political ideology. Age and sociopolitical participation are continuous variables. Sociopolitical participation is represented as an observed variable mean.

$* p<.05 . * * p<.01 . * * * p<.001$.

\section{Confirmatory Factor Analysis}

Evaluating latent mean differences (or bias in sociopolitical participation) and DIF (or bias in the measure) requires that measurement is sound. To this end, a CFA was conducted for the CCS measure of critical action: sociopolitical participation to assess how well the nine corresponding items load onto this latent construct. Maximum likelihood with robust standard errors (MLR) was used in all analyses in order to address some item-level departures from normality (see Table 1). Three item pairs (Q1 and Q3, Q1 and Q4, Q5 and Q8) measure similar activities and/or may share common sources of error variance (Kline, 2015). Correlations between these pairs of error terms were therefore estimated for all subsequent MIMIC analyses.

The CFA suggested the model was a good fit to the data. RMSEA $(0.042,90 \%$ CI: $[0,0.074])$ was desirably below its 0.05 benchmark, SRMR $(0.04)$ was desirably below its 0.06 benchmark, and CFI (0.98) and TLI (0.96) were desirably above their 0.95 benchmarks (Hu \& Bentler, 1999; Kline, 2015). Each item loaded significantly onto the sociopolitical participation construct 
(see Figures 2 and 3). One item, Q7: participated in a discussion about a social or political issue, failed to load as strongly as the others $(\lambda=0.31)$. All other items loaded strongly onto the latent construct. This poorly loading item was removed from the construct, and the CFA was rerun. The resulting fit statistics, Cronbach's alpha, and interitem correlation improved ( $a=$ 0.85; IIC $=0.42 ;$ RMSEA $=0.03,90 \% \mathrm{CI}:[0,0.072] ;$ SRMR $=0.036 ; \mathrm{CFI}=0.99 ; \mathrm{TLI}=0.98)$. Overall, the fit of the original and refitting of the sociopolitical participation variable with this independent data source provides evidence of internal construct validity.

\section{MIMIC Model: Does Political Identification Predict Sociopolitical Participation?}

Following the CFA, we used a MIMIC model to evaluate whether youth identifying as Republican or Democrat exhibited latent mean differences in sociopolitical participation. This analysis was carried out with 160 participants. The decrease in analytic sample size, recall, is due to the exclusion of "other" and "independent" political identities that may exhibit politically disparate views and missing data on some exogenous variables-particularly SES, for which 24 students did not provide a response. Unlike observed means, latent means acknowledge that participant responses are imprecisely measured, thereby making estimates more accurate than observed means by considering measurement error more fully. Overall, the model displayed a satisfactory fit, though some fit measures were slightly below common benchmarks (Hu \& Bentler, 1999; Kline, 2015). RMSEA (0.06) was just above its preferable threshold of 0.05 , and well within its threshold according to its $90 \%$ confidence interval was $(0.03,0.08)$. CFI $(0.93)$ and TLI $(0.90)$ were acceptable, yet marginally below common benchmarks of 0.95 . SRMR $(0.06)$ was below its benchmark of .08 , indicating a good fit.

After adjusting for latent mean differences, the MIMIC model failed to detect any item-level differences by the exogenous covariates used in the MIMIC model. This was evidenced by a lack of statistical significance between exogenous covariates and latent indicators, trivial effect sizes for these non-significant relationships, and an overall satisfactory model fit. Thus, the MIMIC model found that sociopolitical participation did not exhibit measurement bias (DIF). In essence, the measurement of sociopolitical participation was found to be unbiased across the four exogenous covariates within our sample. Due to this, we can assume that differences in sociopolitical participation are free from measurement bias along these identities. The freedom from bias by these four important identities further adds to the validity of the latent sociopolitical participation construct.

The model revealed a significant relationship between youths' race/ethnicity and sociopolitical participation with students of color indicated by 0 and White students coded as 1 . Specifically, the model found a marginal relationship between race/ethnicity and sociopolitical participation, 
suggesting that youth of color engage in slightly more sociopolitical participation than their White peers ( $\beta_{w h i t e}=-0.101, p=0.092$ ). Additionally, the MIMIC found that Republicanidentifying youth engage more frequently in sociopolitical participation than their Democratidentifying peers ( $\left.\beta_{\text {rep }}=0.226, p<0.05\right)$ as evinced by a significant result.

In MIMIC models, standardized coefficients are interpreted as effect sizes. Coefficients between 0.1 and 0.3 correspond to a "small" effect size, coefficients between 0.3 and 0.5 correspond to a "medium" effect size, and coefficients larger than 0.5 correspond to a "large" effect size (Kline, 2015). Neither gender nor SES was found to be a predictor of sociopolitical participation (see Figure 2). Given that the measurement of sociopolitical participation failed to detect DIF, these small effects found in the tests of latent mean differences are not biased by differences in measurement based on youths' political identification, gender, race/ethnicity, or social class, thereby lending additional strength to these inferences.

Figure 2. Multiple Indicator and Multiple Causes (MIMIC) Model With Political Identification as Exogenous Covariate

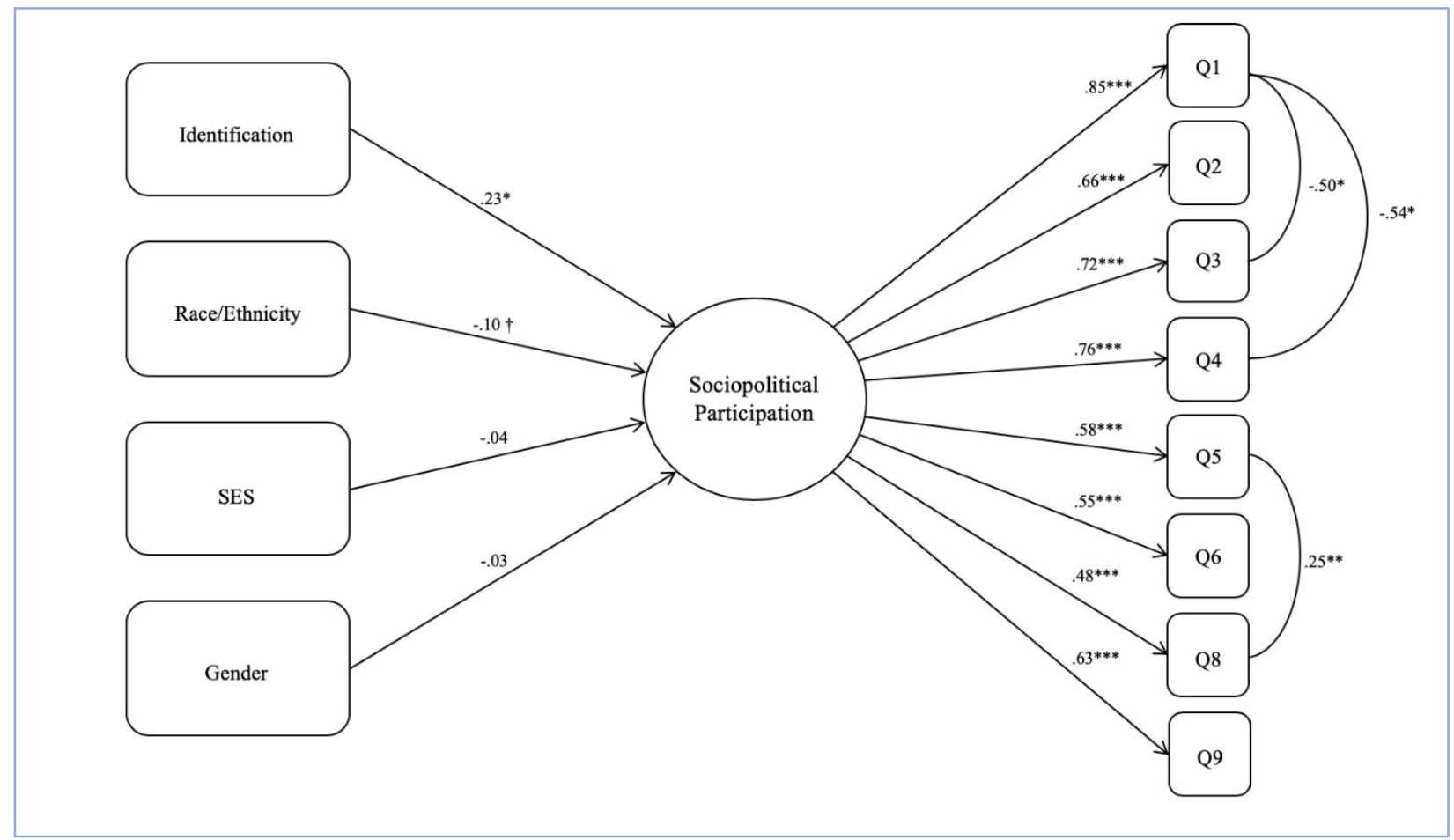

$* * * p \leq .001, * * p \leq .01, * p \leq .05,+p<.07$.

Sensitivity analyses using OLS regression suggested similar directions in sociopolitical participation by political party identification, however these results were not significant. That is, Republicans exhibited more sociopolitical participation than Democrats ( $\beta_{\text {rep }}=0.23 p=.14$ ) like 
in the MIMIC analyses, but at a non-significant level. The overall $R^{2}$ for the model was 0.03 , with 0.02 of the total $R^{2}$ contributed by party identification. This indicates that only $2 \%$ of the variance in sociopolitical participation was explained by political party identification after accounting for gender, race/ethnicity, and social class. This is comparable to the total contribution in the MIMIC model $\left(\beta=0.23 ; 0.23^{2}=0.05\right)$. Taken together, these results suggest that the MIMIC model and the OLS regression model converge to indicate that Republican-identifying youth engage in more frequent sociopolitical participation, but diverge as to whether these differences are statistically significant. In both cases, political party identification has a small effect size, explaining approximately $3 \%$ to $5 \%$ of the variance in sociopolitical participation.

\section{MIMIC Model: Does Political Ideology Predict Sociopolitical Participation?}

A second and separate MIMIC model was used to evaluate whether youth identifying as conservative or liberal exhibited latent mean differences in sociopolitical participation. This analysis was carried out with 205 participants. The decrease in analytic sample size is due to missing data on some independent variables-particularly for SES, for which 24 students did not provide a response, as previously mentioned. In this model, youths' self-identified political ideology (i.e., conservative vs. liberal) was used as an exogenous covariate (see Figure 3). Overall, this model exhibited a similarly adequate fit to the data (RMSEA $=0.05, \mathrm{CFI}=0.96$, $\mathrm{TLI}=0.94, \mathrm{SRMR}=0.05)$.

As with the political identification model, the political ideology model did not find measurement bias in any individual items that measure sociopolitical participation. This was, again, evidenced by a lack of statistical significance between exogenous covariates and latent indicators, trivial effect sizes for these non-significant relationships, and an overall satisfactory model fit. Items reflecting sociopolitical participation were unrelated to whether participants identified as more liberal or conservative, nor were they related to social class, race/ethnicity, gender, or political identification. Students identifying as ideologically liberal were not found to engage in more frequent sociopolitical participation than their conservative-identifying peers ( $\beta_{\text {cons }}=0.09, p=$ 0.18 ) or vice versa as evidence by a non-significant effect. The model found that youth of color engage in more frequent sociopolitical participation than their White peers, though this relationship was only marginally significant ( $\beta_{\text {white }}=-0.11, p=0.06$ ). Gender and SES were found to be non-significant predictors of sociopolitical participation. 
Figure 3. Multiple Indicator and Multiple Causes (MIMIC) Model With Political Ideology as Exogenous Covariate

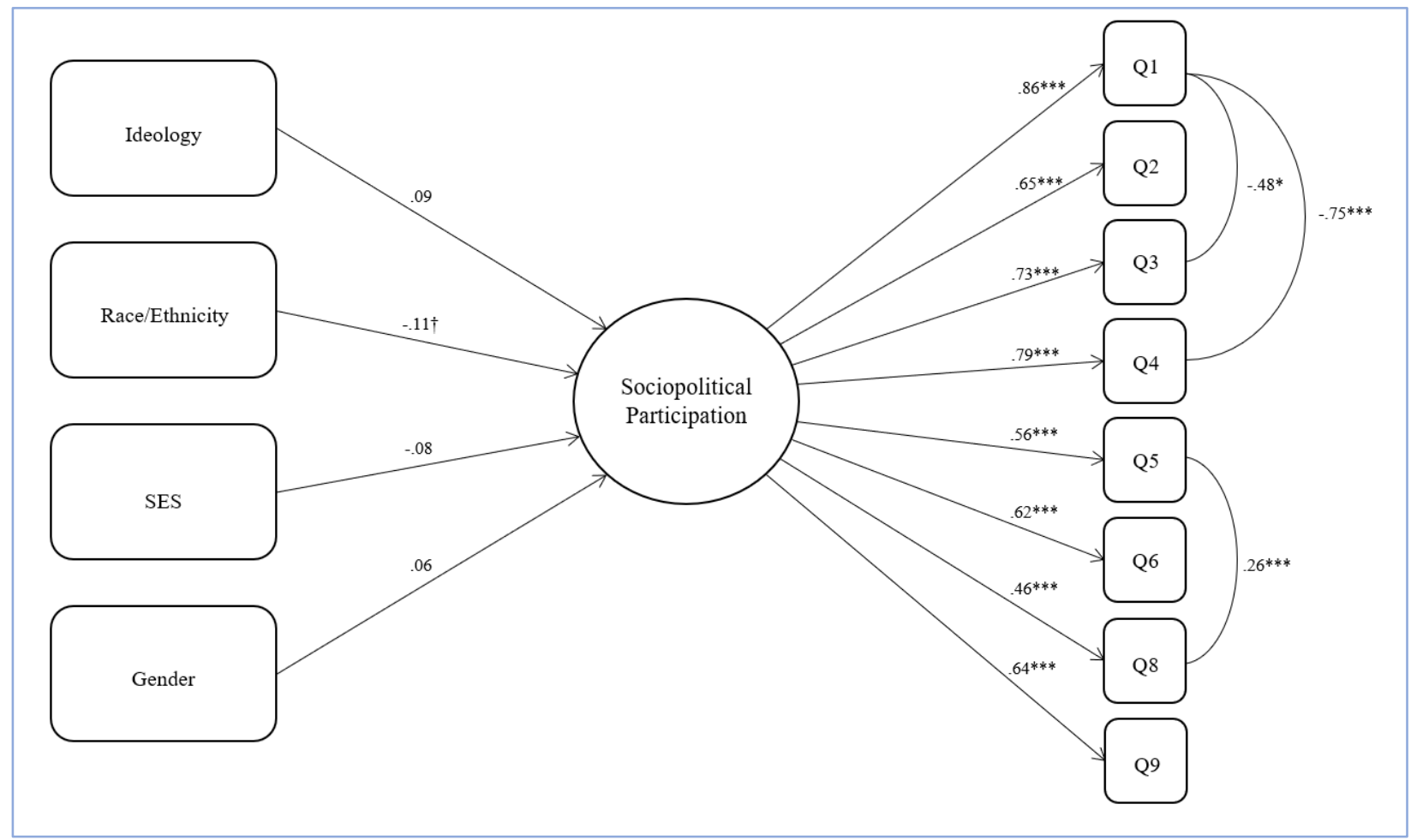

$* * * p \leq .001, * * p \leq .01, * p \leq .05,+p<.07$

Sensitivity analyses using OLS regression suggested only marginal differences in sociopolitical participation by gender. This runs contrary to the findings of the MIMIC model, which suggested a marginal difference in sociopolitical participation by race/ethnicity. The OLS model found that males are marginally more likely to engage in sociopolitical participation than females $\left(\beta=0.18, p=0.09\right.$ ). The overall $R^{2}$ for this model was only 0.03 , suggesting that gender, race/ethnicity, social class, and political ideology only explained a total of $3 \%$ of the variance in sociopolitical participation. Of that 3\%, $2 \%$ was explained by gender. Race/ethnicity was not significant in the OLS regression model, nor was self-identified political ideology. While the MIMIC and OLS models for political ideology diverge on the marginally significant demographic covariates, they both suggest that political ideology is a non-significant variable for explaining variation in sociopolitical participation.

\section{Discussion}

The political attitudes and behaviors of conservative and liberal leaning individuals suggest that those who identify as liberal or Democrat may engage in more sociopolitical participation due to the liberal belief of participation in action to reform society (Whitley \& Yoder, 2015). This translates into the possibility that participation in sociopolitical action and the items used to 


\section{Youth Sociopolitical Participation and Views}

measure it may be biased. In other words, that those with differing political perspectives may engage in and respond to items that measure sociopolitical participation differently. To assess whether this is true, MIMIC models tested whether marginalized youth who identified as liberal or conservative as well as Democrat or Republican reported different levels of sociopolitical participation while also testing for bias at the individual item level. Our results found that political party identification had a significant, yet small association with sociopolitical participation suggesting a trend that Republican identifying youth participate slightly more frequently than those who identify as Democrat. Political ideology evinced no significant difference between those who identify as liberal and conservative in their levels of sociopolitical participation. Neither MIMIC model found evidence of DIF for any sociopolitical participation items, thereby suggesting that within our sample this measure of sociopolitical participation is not biased by political ideology, party identification, or the other covariates tested in the MIMIC models such as race/ethnicity, gender, and SES.

Political party identification has been shown to be an important predictor of how individuals vote (Knight, 1999), but it has been unclear as to whether it would also be associated with how youth participate sociopolitically. Our results found that party identification may play only a very small role in the sociopolitical participation of the youth in our sample. Related work found that political party identification was also only marginally related with critical reflection of perceived inequality-the cognitive component of CC-while political ideology was shown to have a small, significant association (Diemer at el., 2019). These results in tandem with results from the current study, suggest that perhaps political identification is related to behaviors whereas ideology is related more to the thoughts and beliefs that individuals hold about societal inequality aligning with previous findings that ideology is associated with political beliefs more than party identification (Knight, 1999).

Additionally, the results of our linear regression analyses aligned with the direction of the party identification findings, however these sensitivity analyses failed to reaffirm the statistical significance found in the MIMIC model suggesting that Republican identifying youth engage in more frequent sociopolitical participation. The fact that the MIMIC results were not replicated in the OLS regressions perhaps signifies a weak relationship between political party identification and sociopolitical participation. Further, in both regression models, results found that the political predictor variables explained less than $5 \%$ of the overall variance in sociopolitical participation. If sociopolitical participation was indeed biased by left-leaning ideology, then we would expect the measurement of sociopolitical participation to exhibit DIF corresponding to both political ideology and party identification. In other words, these results provide empirical evidence that largely challenges the supposition that sociopolitical participation is politically 


\section{Youth Sociopolitical Participation and Views}

biased and supports previous scholarship that refutes that the broader construct of CC is similarly biased (Diemer et al., 2019).

In both MIMIC models, there were no significant differences between gender and SES groups for either political party identification or ideology, although there was a small significant and marginal relationship between racial groups in both models, suggesting that students of color are participating at higher levels of sociopolitical participation than their White peers. In an examination of civic engagement over a 30-year span, Gaby (2017) found that people of color actually participated less than Whites in electoral politics, volunteering, and social movement participation. However, separate empirical work has found that when SES is controlled for, African Americans are actually significantly more likely to attend a protest or demonstration (Beyerlein \& Hipp, 2006) suggesting that there is nuance in participation depending on the type of action being examined.

Our finding that gender is not related to sociopolitical participation does not align with prior research that has found differences among these groups. For instance, previous scholarship has found that women engage in political behaviors at lower rates than their male peers (Inglehart \& Norris, 2003). However, this varies when the type of political behavior is considered. Adolescent girls in the United States expressed a higher anticipation of engaging in behaviors such as voting, volunteering, and protesting than did their male peers (Hooghe \& Stolle, 2004). The same study found that boys were less drawn to those same behaviors-which were deemed as "social movement" types of actions-but were more likely to anticipate participating in activities that seemed to exhibit leadership such as running for an elected position. Given ample evidence that suggests differences in women's and men's sociopolitical participation, the lack of association between gender and sociopolitical participation is intriguing. Perhaps for the students in our sample, there may be less opportunity to engage in a variety of activities that would show gender-based patterns of engagement. Further, as students are likely engaging in school-based activities, they may be limited in their availability to diversify their engagement outside of school, given the demands of their daily school engagement.

Similarly, our null finding between the association between SES and sociopolitical participation contradicts previous research. A majority of prior work suggests that individuals from less affluent backgrounds tend to be less involved in political engagement as opposed to those who come from higher SES background (Laurison, 2016). A large proportion of the participants in our study, identified with marginalized backgrounds by virtue of race/ethnicity or SES, so this lack of variation may explain our finding that SES did not associate with sociopolitical 
participation. This calls for future research to examine similar questions with a sample of marginalized youth similar to those in this study that are more socioeconomically diverse.

As mentioned above, our sample was unique in the sense that it purposefully consisted of a sample of high school students that were marginalized either racially, socioeconomically, or both in a swing state. Furthermore, they were average high school students, not specifically youth who identified as activists or particularly socially active. Our results are not intended to be generalizable to the larger population, but rather exemplify how students from marginalized backgrounds who differ on political ideology and identification participate in politically based behaviors. Although, unique due to these characteristics, the proportion of our participants who identified as liberal versus conservative and Democratic versus Republican mirror nationwide trends, in that the large majority of youth-and those of color, especially-identify as Democrat and liberal (Center for Information \& Research on Civic Learning and Engagement [CIRCLE], 2019). Pockets of similarly identifying marginalized youth can be found in many cities around this nation. Further research should continue to examine how the sociopolitical participation of these youth may differ from a nationwide sample.

\section{Policy Implications and Practical Applications}

The belief that sociopolitical participation is biased and is only engaged by those who have liberal ideals has implications for programming and policy that affects the development of youth political engagement. This study provides evidence that these behaviors are hardly explained by political perspective, which can translate into an increased adoption of programs that promote these actions within marginalized youth. A 2018 post by the National Education Association (Walker, 2018) discussed how much of American discourse is currently labelled as "political" or "partisan." Our findings can help negate notions that engaging youth in sociopolitical action is partisan and does not strongly lean in either political direction. Refuting claims of partisanship and indoctrination can help to further develop and create opportunities for youth to voice their opinions and share their perspectives on issues important to them.

Further, these findings support that youth sociopolitical participation is not merely a manifestation of political indoctrination, but rather that this participation is associated with prosocial and positive outcomes. For instance, research has found positive outcomes are associated with CC interventions for marginalized youth (Cabrera et al., 2014) such as sense of agency, generating interest for social change, and maintaining commitment to such behaviors into adulthood (Flanagan, 2004; Youniss et al., 1997). Schools may be more apt to adopt this measure of sociopolitical participation as a quantitative way to gauge the extent to which their students are participating in such activity if it is viewed as not simply being representative of 
one political perspective. The creation of opportunities for youth from different backgrounds with diverse beliefs and perspectives is imperative not only for the future of our democracy, but also for the healthy development of young people (Diemer et al., 2021). Further, understanding that sociopolitical actions are not just reserved for one type of person is important for practitioners, researchers, activists, and educators to realize so that social and political organizations and schools are welcoming spaces for all youth to engage with.

\section{Limitations and Future Directions}

Although MIMIC models are well-suited for this type of analyses, one limitation is that this methodology forces exogenous covariates in the model to be dichotomized in order to more easily detect differences between two groups. We recognize that there is a spectrum of political perspectives and beliefs to be considered. Our original data consisted of responses that represented more variability, for example strength of political ideology was measured (e.g., strongly liberal, slightly liberal, so on). However, we were forced to group responses such as "slightly conservative" with "strongly conservative" in order to have the dichotomous options of conservative and liberal.

Additionally, we were forced to collapse youth who came from various groups into one larger group labeled people of color. This was necessary for our analyses and to have large enough sample sizes to make adequate comparisons. However, this grouping does not allow for us to take into consideration the heterogeneity and variability that is present within populations of youth of color. Further, all participants reside in the same geographic region which does not allow for our findings to be generalizable to other areas. For these reasons, future work should explore these associations in additional geographic regions while still attending to racial and ethnic group differences in sociopolitical participation.

Lastly, the items included in this study measuring sociopolitical action may not represent the full range of actions that youth are participating in. The items in our measure reflect traditional actions like participating in organization, contacting news media or local officials, signing a petition, or joining a protest march. Such actions may not be equally accessible to youth under the age of 18 , and even more so, marginalized youth, who may not have full access due to lack of opportunity structures in their community.

\section{Conclusion}

A lack of diverse political perspectives for those who engage in sociopolitical action would be detrimental to our democracy. As stated by Watts and Flanagan (2007) uneven participation in "the civic and political process raises questions about the discrepancy between ideal and real- 
world democracy" (pg. 787). Uneven participation would translate into only a certain set of ideas and perspectives being considered in an effort towards social change and the improvement of societal and political conditions. A liberal bias would suggest that more conservative views and perspectives are foreclosed upon and those more conservative approaches to social problems are left out of the conversation. However, using MIMIC modeling this study provides initial empirical evidence that sociopolitical participation among marginalized youth may not biased toward youth who hold more liberal values, but in fact suggests that Republican-identifying youth are reporting slightly higher levels of sociopolitical participation in our sample, although these findings were not significantly replicated in subsequent regression analyses. These results suggest that diverse populations of youth across different political perspectives are engaged in the political system through their sociopolitical participation at similar levels.

\section{Author Note}

Correspondence concerning this article should be addressed to Aixa D. Marchand, Department of Psychology, Rhodes College, Memphis, TN 38112, USA. Email: marchanda@rhodes.edu.

\section{References}

Adler, R. P., \& Goggin, J. (2005). What do we mean by "civic engagement"? Journal of Transformative Education, 3(3), 236-253. (https://doi.org/10.1177/1541344605276792)

Anyiwo, N., Bañales, J., Rowley, S. J., Watkins, D. C., \& Richards-Schuster, K. (2018). Sociocultural influences on the sociopolitical development of African American youth. Child Development Perspectives. 12, 165-170. (https://doi.org/10.1111/cdep.12276)

Ballard, P. J. (2016). Longitudinal links between discrimination and civic development among Latino and Asian adolescents. Journal of Research on Adolescence, 26, 723-737. (https://doi.org/10.1111/jora.12221)

Beyerlein, K., \& Hipp, J. R. (2006). From pews to participation: The effect of congregation activity and context on bridging civic engagement. Social Problems, 53(1), 97-117. (https://doi.org/10.1525/sp.2006.53.1.97)

Bronfenbrenner, U. (1979). The ecology of human development: Experiments by nature and design. Harvard University Press.

Cabrera, N. L., Milem, J. F., Jaquette, O., \& Marx, R. W. (2014). Missing the (student achievement) forest for all the (political) trees: Empiricism and the Mexican American studies controversy in Tucson. American Educational Research Journal, 51(6), 1084-1118. (https://doi.org/10.3102/0002831214553705) 
Journal of Youth Development | http://jyd.pitt.edu/ | Vol. 16 Issue 5 DOI 10.5195/jyd.2021.1089 Youth Sociopolitical Participation and Views

Center for Information \& Research on Civic Learning and Engagement (2019). Growing Voters: Engaging Youth Before They Reach Voting Age to Strengthen Democracy. (https://civicyouth.org/growingvoters-engaging-youth-before-they-reach-voting-age-to-strengthen-democracy/)

Cole, E. R. (2009). Intersectionality and research in psychology. American Psychologist, 64(1), 170-180. (https://doi.org/10.1037/a0014564)

DeAngelo, L., Schuster, M. T., \& Stebleton, M. J. (2016). California DREAMers: Activism, identity, and empowerment among undocumented college students. Journal of Diversity in Higher Education, 9(3), 216. (https://doi. org/10.1037/dhe0000023)

Diemer, M. A., \& Li, C. H. (2011). Critical consciousness development and political participation among marginalized youth. Child Development, 82(6), 1815-1833. (https://doi.org/10.1111/j.14678624.2011.01650.x)

Diemer, M. A., Mistry, R. S., Wadsworth, M. E., López, I., \& Reimers, F. (2013). Best practices in conceptualizing and measuring social class in psychological research. Analyses of Social Issues and Public Policy, 13(1),77-113. (https://doi.org/10.1111/asap.12001)

Diemer, M. A., Pinedo, A., Bañales, J., Mathews, C. J., Frisby, M. B., Harris, E. M., \& McAlister, S. (2021). Recentering action in critical consciousness. Child Development Perspectives, 15(1), 12-17. (https://doi.org/10.1111/cdep.12393)

Diemer, M. A., \& Rapa, L. J. (2016). Unraveling the complexity of critical consciousness, political efficacy, and political action among marginalized adolescents. Child Development, 87(1), 221-238. (https://doi.org/10.1111/cdev.12446)

Diemer, M. A., Rapa, L. J., Park, C. J., \& Perry, J. C. (2017). Development and validation of the critical consciousness scale. Youth \& Society, 49(4), 461-483. (https://doi.org/10.1177/0044118X14538289)

Diemer, M. A., Rapa, L. J., Voight, A. M., \& McWhirter, E. H. (2016). Critical consciousness: A developmental approach to addressing marginalization and oppression. Child Development Perspectives, 10(4), 216-221. (https://doi.org/10.1111/cdep.12193)

Diemer, M. A., Voight, A. M., Marchand, A., \& Bañales, J. (2019). Political identification, political ideology, and critical social analysis of inequality among marginalized youth. Developmental Psychology, 55(3), 538-549. (https://doi.org/11.1037/dev0000559)

Enders, C. K., \& Bandalos, D. L. (2001). The relative performance of full information maximum likelihood estimation for missing data in structural equation models, Structural Equation Modeling: $A$ Multidisciplinary Journal, 8:3, 430- 457. (https://doi.org/10.1207/S15328007SEM0803_5)

Erikson, E. H. (1968). Identity: Youth and crisis. Norton.

Flanagan, C. A. (2004). Volunteerism, leadership, political socialization, and civic engagement. In Lerner, R. M., \& Steinberg, L. (Eds.). Handbook of Adolescent Psychology (721-746). Wiley.

Freire, P. (1993). Pedagogy of the oppressed. Continuum. 
Journal of Youth Development | http://jyd.pitt.edu/ | Vol. 16 Issue 5 DOI 10.5195/jyd.2021.1089 Youth Sociopolitical Participation and Views

Gaby, S. (2017). The civic engagement gap(s): Youth participation and inequality from 1976 to 2009. Youth \& Society, 49(7), 923-946. (https://doi.org/10.1177/0044118X16678155)

Ginwright, S. A. (2015). Radically healing Black lives: A love note to justice. New directions for student leadership, 2015(148), 33-44. http://dx.doi.org/ 10.1002/yd.20151)

Hooghe, M., \& Stolle, D. (2004). Good girls go to the polling booth, bad boys go everywhere: Gender differences in anticipated political participation among American fourteen-year-olds. Women, \& Politics, 26(3-4), 1-23. (https://doi.org/10.1300/j014v26n03_01)

Hope, E. C., Gugwor, R., Riddick, K. N., \& Pender, K. N. (2019). Engaged against the machine: Institutional and cultural racial discrimination and racial identity as predictors of activism orientation among Black youth. American Journal of Community Psychology, 63, 61-72. (https://doi.org/10.1002/ajcp.12303)

Hope, E. C., Keels, M., \& Durkee, M. I. (2016). Participation in Black Lives Matter and deferred action for childhood arrivals: Modern activism among Black and Latino college students. Journal of Diversity in Higher Education, 9(3), 203. (https://doi.org/10.1037/dhe0000032)

Hope, E. C., \& Spencer, M. B. (2017). Civic engagement as an adaptive coping response to conditions of inequality: An application of phenomenological variant of ecological systems theory (PVEST). In Handbook on positive development of minority children and youth (pp. 421-435). (http://dx.doi.org/ 10.1007/978-3-319-43645-6_25)

Hu, L. T., \& Bentler, P. M. (1999). Cutoff criteria for fit indexes in covariance structure analysis: Conventional criteria versus new alternatives. Structural Equation Modeling, 6(1),1-55. (https://doi.org/10.1080/10705519909540118)

Inglehart, R., \& Norris, P. (2003). Rising tide: Gender equality and cultural change around the world. Cambridge University Press.

Jennings, M. K., \& Niemi, R. G. (1968). The transmission of political values from parent to child. $A m$. Political Sci. Rev. 62(1), 169-184. (https://doi.org/10.2307/1953332)

Kline, R. B. (2015). Principles and practice of structural equation modeling: Methodology in the social sciences ( $4^{\text {th }}$ ed.). Guilford Press.

Knight, K. (1999). Liberalism and conservatism. In J. P. Robinson, P. R. Shaver, \& L. S. Wrightsman (Eds.), Measures of political attitudes (pp. 59-158). Academic Press.

Laurison, D. (2016). Social class and political engagement in the United States. Sociology Compass, 10(8), 684-697. (https://doi.org/10.1111/soc4.12390)

Muthén, L. K., \& Muthén, B. (2017). Mplus user's guide: Statistical analysis with latent variables, user's guide. Muthén \& Muthén.

Ortega-Williams, A., Wernick, L. J., DeBower, J., \& Brathwaite, B. (2020). Finding relief in action: The intersection of youth-led community organizing and mental health in Brooklyn, New York City. Youth \& Society, 52(4), 618-638. (http://dx.doi.org/10.1177/0044118X18758542) 
Journal of Youth Development | http://jyd.pitt.edu/ | Vol. 16 Issue 5 DOI 10.5195/jyd.2021.1089 Youth Sociopolitical Participation and Views

Patterson, M. M., Bigler, R. S., Pahlke, E., Brown, C. S., Hayes, A. R., Ramirez, M. C., \& Nelson, A. (2019). Toward a developmental science of politics. Monographs of the Society for Research in Child Development, 84(3), 7-185. (https://doi.org/10.1111/mono.12410)

Torney-Purta, J., Lehmann, H., Oswald, W., \& Schulz, W. (2001). Citizenship and education in twentyeight countries: Civic knowledge and engagement at age fourteen. International Association for the Evaluation of Educational Achievement.

Walker, T. (2018, December 11). "Education is political": Neutrality in the classroom shortchanges students. NEA, (https://www.nea.org/advocating-for-change/new-from-nea/education-politicalneutrality-classroom-shortchanges-students)

Watts, R. J., Diemer, M. A., \& Voight, A. M. (2011). Critical consciousness: Current status and future directions. New directions for child and adolescent development, 2011(134), 43-57. (https://doi.org/10.1002/cd.310)

Watts, R. J., \& Flanagan, C. (2007). Pushing the envelope on youth civic engagement: A developmental and liberation psychology perspective. Journal of community psychology, 35(6), 779-792. (https://doi.org/10.1002/jcop.20178)

Watts, R. J., Griffith, D. M., \& Abdul-Adil, J. (1999). Sociopolitical development as an antidote for oppression - Theory and action. American Journal of Community Psychology, 27(2), 255-271. (https://doi.org/10.1023/A:1022839818873)

Watts, R. J., Williams, N. C., \& Jagers, R. J. (2003). Sociopolitical development. American Journal of Community Psychology, 31, 185-194. (https://doi.org/10.1023/A:1023091024140)

Whitley, C. T., \& Yoder, S. D. (2015). Developing social responsibility and political engagement: Assessing the aggregate impacts of university civic engagement on associated attitudes and behaviors. Education, Citizenship and Social Justice, 10(3), 217-233. (https://doi.org/10.1177/1746197915583941)

Wray-Lake, L., Arruda, E. H., \& Hopkins, D. A. (2019). The party goes on: US young adults' partisanship and political engagement across age and historical time. American Politics Research, 57(6), 13581375. (https://doi.org/10.1177/1532673X198449692)

Verba, S. (2003). Would the dream of political equality turn out to be a nightmare? Perspectives on Politics 1(4), 663-679. (https://doi.org/10.1017/S1537592703000458)

Youniss, J., McLellan, J. A., \& Yates, M. (1997). What we know about engendering civic identity. American Behavioral Scientist, 40(5), 620-631. (https://doi.org/10.1177/0002764297040005008) 